\title{
Coupled physicochemical and bacterial reduction mechanisms for passive remediation of sulfate- and metal-rich acid mine drainage
}

\begin{abstract}
Treatment of acid mine drainage (AMD) highly rich in sulfate and multiple metal elements has been investigated in a continuous flow column experiment using organic and inorganic reactive media. Treatment substrates that composed of spent mushroom compost (SMC), limestone, activated sludge and woodchips were incorporated into bacterial sulfate reduction (BSR) treatment for AMD. SMC greatly assisted the removals of sulfate and metals and acted as essential carbon source for sulfate-reducing bacteria (SRB). Alkalinity produced by dissolution of limestone and metabolism of SRB has provided acidity neutralization capacity for AMD where $\mathrm{pH}$ was maintained at neutral state, thus aiding the removal of sulfate. $\mathrm{Fe}$, $\mathrm{Pb}, \mathrm{Cu}, \mathrm{Zn}$ and $\mathrm{Al}$ were effectively removed (87-100\%); however, Mn was not successfully removed despite initial $\mathrm{Mn}$ reduction during early phase due to interference with Fe. The first half of the treatment was an essential phase for removal of most metals where contaminants were primarily removed by the BSR in addition to carbonate dissolution function. The importance of BSR in the presence of organic materials was also supported by metal fraction analysis that primary metal accumulation occurs mainly through metal adsorption onto the organic matter, e.g., as sulfides and onto Fe/Mn oxides surfaces.
\end{abstract}

Keyword: Acid mine drainage; Physicochemical; Bacterial reduction mechanisms; Treatment substrate 